\title{
Dismantling a myth: the correlation between ammonium levels and severity of hypoxic-ischemic encephalopathy. could it be an effect of hypothermia?
}

\begin{abstract}
Introduction: It is still not clear what specific value of hyperammonemia causes brain damage in critical patients, specifically in patients diagnosed with hypoxic-ischemic encephalopathy.

Objective: To evaluate ammonium levels in neonates diagnosed with hypoxic-ischemic encephalopathy subjected to hypothermic therapy and their relation to the other variables in hypoperfusion.

Methodology: Analytic observational study of neonates diagnosed with hypoxic-ischemic encephalopathy treated with cerebral hypothermia in which blood ammonium levels were compared to other hypoperfusion variables such as $\mathrm{Ph}$, base excess, magnesium, lactate, and with the presence of seizures and death to determine whether a correlation existed.

Results: The average serum ammonium level was $57.45 \mu \mathrm{mol} / \mathrm{lt}$, and there were only two patients with ammonium levels above $110 \mu \mathrm{mol} / \mathrm{lt}$. Most patients had seizures and four patients died. There was no correlation found between ammonium and the other hypoperfusion variables, with values of $\mathrm{R} 2<0.1$. Neither was a correlation found between the presence of seizures and death (R2 0.203 and 0.005 respectively).

Conclusion: In neonates diagnosed with hypoxic-ischemic encephalopathy managed with hypothermia, the values for serum ammonium do not correlate to the severity of the encephalopathy for the short-term prognosis. For this reason, it cannot be assumed that hyperammonemia is caused for hypoxia, and it is necessary to look for differential diagnoses for hyperammonemia
\end{abstract}

Keywords: Hyperammonemia, Ammonium Compounds, Hypoxia-Ischemia, Brain Hypothermia
Volume 3 Issue 3 - 2015

\author{
Monica D’Amato Gutierrez,' Andrés Felipe \\ Uribe, ${ }^{2}$ Carolina Serrano Tabares ${ }^{3}$ \\ 'Department of Pediatrics, Universidad Pontificia Bolivariana, \\ Colombia \\ ${ }^{2}$ Neonatal Intensive Care Unit, Clinica Universitaria Bolivariana, \\ Colombia \\ ${ }^{3}$ Department of Pediatrics, Universidad, Clinica Universitaria \\ Bolivariana, Colombia
}

Correspondence: Carolina Serrano Tabares, Street 78b No. 72a - 19, Medellin, Antioquia, Colombia, Tel 9842 \& 3006203735, Email caropaisa@gmail.com

Received: July 18, 2015 | Published: November 09, 2015
Abbreviations: BE, Base Excess; HIE, Hypoxic-Ischemic Encephalopathy

\section{Introduction}

Ammonium as a product of protein and nitrogenated bases metabolism is a source of nitrogen for the amino acids synthesis and for maintaining the body's acid-base balance. Normal blood levels for neonates vary according to the gestational age, with fullterm newborn babies having a normal value of $45 \pm 9 \mu \mathrm{mol} / \mathrm{L}$, with a tolerable maximum of up to $80-90 \mu \mathrm{mol} / \mathrm{lt}$, and for pre-term neonates values of up to $71 \pm 26 \mu \mathrm{mol} / \mathrm{L}$. Hyperammonemia is defined as having these concentrations above $110 \mu \mathrm{mol} / \mathrm{lt}$. Some authors have classified it as mild between 110 and $180 \mu \mathrm{mol} / \mathrm{lt}$, moderate between 180 and $350 \mu \mathrm{mol} / \mathrm{lt}$, and severe when the values exceed $350 \mu \mathrm{mol} / \mathrm{tt}^{1-7}$

The brain is one of the main organs affected by elevated ammonium levels, where edema astrocytes and mitochondrial dysfunction take place, leading to seizures, coma, cognitive damage, and even patients' death. Hyperammonemia is thus a medical emergency and this is why it is important to have timely detection and management to reduce the damage.

Knowing that hyperammonemia has these deleterious effects on the brain, and that it is still unclear which specific level causes brain damage in critical patients, we decided to carry out this research intended to evaluate the levels of ammonium in newborn babies with a diagnosis of hypoxic-ischemic encephalopathy (HIE), and to determine whether a relationship exists between ammonium and other lab values, such as the hypoperfusion indicators, that are known to change in these patients..$^{1-3,6,8-10}$

\section{Materials and methods}

\section{General objective}

To evaluate the levels of ammonium in neonates with hypoxicischemic encephalopathy subjected to hypothermic therapy, and their relationship with the other hypoperfusion variables.

\section{Methodology}

This is an analytical observational study. After obtaining authorization from the institution, data were gathered from the medical records of patients diagnosed with hypoxic-ischemic encephalopathy that had been subjected to hypothermic therapy between January 2011 and April 2015 at ClinicaUniversitariaBolivariana in Medellin, Colombia. Data from 63 patients were collected, but those who did not have ammonium levels were excluded, which left a total of 50 patients.

Quantitative ( $\mathrm{Ph}$, base excess, ammonium, sodium, magnesium, lactate) and qualitative (seizures) variables were evaluated and placed in a database that had been previously designed by the researchers using Microsoft Excel. The database coded the qualitative variables, assigning a 1 for the presence and a 2 for the absence of seizures. For the variables $\mathrm{Ph}$ and base excess, the values were measured at three 
different times, according to the institutional protocol: first six hours of life of the patient, between 6 and 72 hours of life and being on hypothermic therapy, and after 72 hours of hypothermic therapy. In the case ofplasma lactate, measurements were taken between 6 and 72 hours under hypothermic therapy.

To verify whether a relationship existed between the (dependent) variable ammonium and each of the other (independent) variables, dispersion charts were made. The data were then input into the Minitab 17.0 statistical software in such a way as to select the regression model that best fit the observations. A value of $\mathrm{r} 2$ greater than or equal to 0.65 was considered acceptable, as indicated by some authors. ${ }^{11}$

With respect to bias, there was a selection bias because patients who did not have a record of their ammonium levels were excluded at the onset.

\section{Results}

For the 50 patients analyzed, the average level of plasma ammonium was $57.45 \mu \mathrm{mol} / \mathrm{lt}$, with the lowest value being $16.6 \mu \mathrm{mol} /$ lt and the highest $135 \mu \mathrm{mol} / \mathrm{lt}$. There were only two patients with ammonium levels above $110 \mu \mathrm{mol} / \mathrm{lt}$ (Table 1).

Table I Laboratory serum levels.

\begin{tabular}{ll}
\hline Variable & $\begin{array}{l}\text { Number of patients (\%) } \\
\mathbf{n}=50\end{array}$ \\
\hline Ammonium & \\
$<50 \mu \mathrm{mol} / \mathrm{lt}$ & $19(38)$ \\
$50-100 \mu \mathrm{mol} / \mathrm{lt}$ & $29(58)$ \\
$100-110 \mu \mathrm{mol} / \mathrm{tt}$ & 0 \\
$>110 \mu \mathrm{mol} / \mathrm{lt}$ & $2(4)$ \\
Lactate & \\
$<1 \mathrm{mmol} / \mathrm{lt}$ & $1(2)$ \\
$\mathrm{I}-2 \mathrm{mmol} / \mathrm{lt}$ & $5(10)$ \\
$2-5 \mathrm{mmol} / \mathrm{lt}$ & $30(60)$ \\
$>5 \mathrm{mmol} / \mathrm{lt}$ & $14(28)$ \\
Base Excess (BE) between 6 and 72 hours & \\
$<-10 \mathrm{mEq} / \mathrm{lt}$ & $36(72)$ \\
Between - I0- I6 mEq/lt & $9(18)$ \\
$>-16 \mathrm{mEq} / \mathrm{lt}$ & $5(10)$ \\
Ph between 6 and 72 hours & \\
-7 & 0 \\
7 a 7,2 & $5(10)$ \\
$>7,2$ & $45(90)$ \\
\hline
\end{tabular}

*BE: Base Excess

The average level of serum lactate between 6 and 72 hours on hypothermic therapy was $4.07 \mathrm{mmol} / \mathrm{lt}$, with the lowest value being $0.9 \mathrm{mmol} / \mathrm{lt}$ and the highest $17 \mathrm{mmol} / \mathrm{lt}$; there were 15 patients with lactate levels above $5 \mathrm{mmol} / \mathrm{lt}$ (Table 1 ). The patient with the highest lactate levels $(17 \mathrm{mmol} / \mathrm{lt})$ had an ammonium level of less than $50 \mu \mathrm{mol} / \mathrm{lt}(37 \mu \mathrm{mol} / \mathrm{lt})$.

Table 2 Regression coefficient $r 2$ and $p$ values

\begin{tabular}{lll}
\hline Ammonium & R2 & P value \\
\hline $\mathrm{Ph}<6 \mathrm{~h}$ & 0,024 & 0,342 \\
$\mathrm{Ph} 6-72 \mathrm{~h}$ & 0,0006 & $0,87 \mathrm{I}$ \\
$\mathrm{Ph}>72 \mathrm{~h}$ & 0,0854 & 0,079 \\
$\mathrm{BE}<6 \mathrm{~h}$ & 0,0239 & 0,354 \\
$\mathrm{BE} 6-72 \mathrm{~h}$ & 0,0719 & 0,065 \\
$\mathrm{BE}>72 \mathrm{~h}$ & 0,0035 & 0,729 \\
Lactic acid 6-72h & $0,000 \mathrm{I}$ & 0,938 \\
Sodium & 0,0214 & $0,3 \mathrm{I}$ \\
Magnesium & 0,0042 & 0,655 \\
\hline
\end{tabular}

*h: hours; BE: Base Excess.
With respect to the values for base excess and Ph between 6 and 72 hours under hypothermic management, most patients remained acidotic but with values greater than 7.2 for $\mathrm{Ph}$ and $<-10 \mathrm{mEq} / \mathrm{lt}$ for base excess (Table 1).

The two patients with ammonium levels above $110 \mu \mathrm{mol} / \mathrm{lt}$ (levels of 134 y $135 \mathrm{umol} / \mathrm{lt}$ ) had Phvalues indicating acidosis up to 72 hours after being under hypothermic therapy, but improved their acid base compared to the base excess levels (levels of $-12 \mathrm{meq} / \mathrm{lt}$ a $-8.2 \mathrm{meq} / \mathrm{lt}$ and $-16 \mathrm{meq} / \mathrm{lt}$ a $-4.3 \mathrm{meq} / \mathrm{lt}$ respectively).

The average sodium levels were $135.2 \mathrm{meq} / \mathrm{lt}$ and magnesium $2.03 \mathrm{mg} / \mathrm{dl}$, both within the normal range. Respect the outcomes, of all our patients, 36 (72\%) had clinical seizures, and 4 patients died without any seizure.

No correlation was found when ammonium levels were compared to each of the other variables (Table 2). No correlation was found between ammonium levels and $\mathrm{Ph}$ or $\mathrm{BE}$, or in comparisons of ammonium and lactate values taken between 6 and 72 hours on hypothermic therapy; between the values of ammonium and plasma magnesium (Figures 1, $2 \& 3$ ). Neither there was a correlation found between levels of ammonium and the presence of seizures and death, with $R 2$ values of 0.203 and 0.005 respectively.

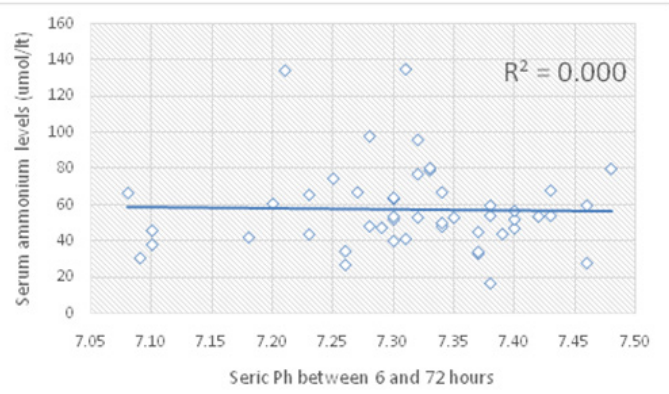

Figure I Values for ammonium $(\mathrm{Y})$ compared to $\mathrm{Ph}(\mathrm{X})$ values between 6 and 72 hours on hypothermic therapy.

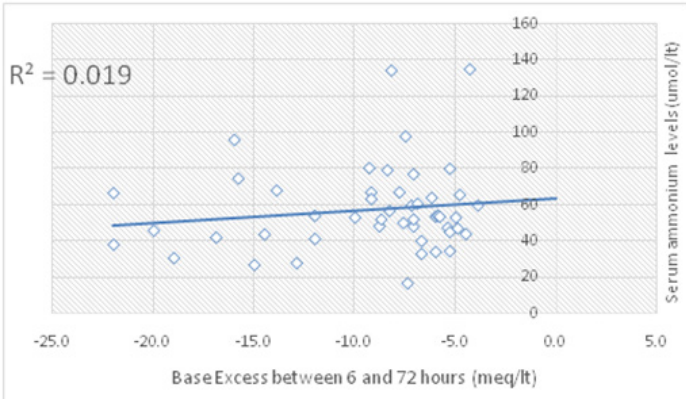

Figure 2 Ammonium levels (Y) compared to Base Excess levels (BE) (X) between 6 and 72 on hypothermic therapy.

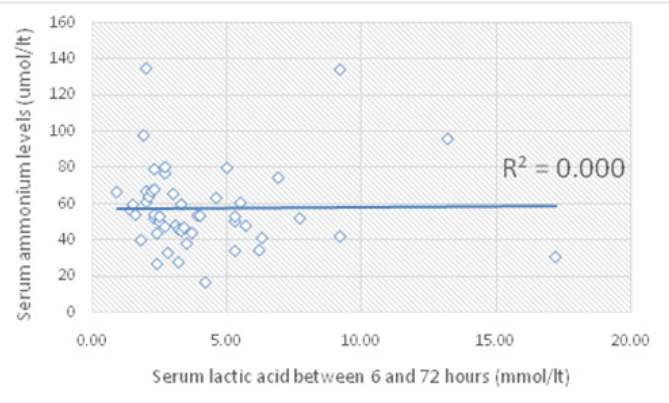

Figure 3 Values for ammonium (Y) compared to values for Lactic Acid (X) between 6 and 72 hours on hypothermic therapy. 


\section{Discussion}

It is clear that hyperammonemia causes multi-systemic damages that significantly affect the brain, but in patients with HIE it is not certain what ammonium levels correlate to the seriousness of the encephalopathy. It has been determined that there is a need to find out the impact of plasma ammonium levels on the seriousness of the patient's condition to define whether the therapy needs to be modified.

After an exhaustive review of the national and international literature, no studies like ours were found which describe the behavior of plasma ammonium levels and their relationship to the other hypoperfusion values in newborn patients with HIE.

Ozanne et al. ${ }^{12}$ studied patients with hyperammonemia due to an alteration in the urea cycle and to liver failure. Most patients developed hyperammonemia for causes other than liver failure. They concluded that ammonium is indeed a marker for mortality but cannot be identified as a causal agent. Lichter-Konecki et al. ${ }^{8}$ has found that, in patients with encephalopathy due to hyperammonemia, hypothermic therapy lowers plasma ammonium levels and passage into the brain.

Patients diagnosed with HIE have multi-organ involvement, the most important of which are the liver and the brain. In addition, as part of the hepatic dysfunction, there is an increase in ammonium plasma levels, which can become a toxic substance and exacerbate brain damage. In our study, we attempted to determine whether there is a correlation between plasma ammonium levels and other hypoper fusion variables and, based on statistical data for the coefficient of determination and $\mathrm{P}$ value, no relationship was found.

The study by Galal et al. ${ }^{4}$ found results similar to ours, but theirs were not patients diagnosed with HIEor of neonatal ages. They did not find a relationship between ammonium levels and blood levels for glucose, electrolytes, arterial gases, or liver or kidney function tests. There was no statistical significance to the levels of ammonium and the patients' final outcome $(\mathrm{p}=0.478)$.

In our study, we found that in patients with HIEsubjected to hypothermic therapy, ammonium serum levels did not exhibit a behavior that related to the underlying disease nor the state of hypoperfusion. For this reason, elevated ammonium values cannot be interpreted as secondary to a severe disease.

\section{Conclusion}

We conclude that in newborn patients diagnosed with HIE being managed with hypothermia, plasma ammonium levels do not correlate to the severity of the encephalopathy or to the short-term prognosis.
Therefore, it should not be assumed, as it has classically been done, that hyperammonemia is a cause of hypoxia and brain damage, and these patients should be subjected to a search for a differential diagnosis for hyperammonemia.

\section{Acknowledgments}

None.

\section{Conflicts of interest}

None.

\section{References}

1. Nogales A, López K, Navarro D, et al. Hyperammonaemia in children: classification and therapeutic options. Gen. 2013;67(1):11-15.

2. Usmani SS, Cavaliere T, Casatelli J, et al. Plasma ammonia levels in very low birth weight preterm infants. J Pediatr. 1993;123(5):797-800.

3. http://ae3com.eu/noticias/protocolo-hispano-luso-hiperonemias.pdf

4. Galal NM, Fouad HM, Saied A, et al. Hyperammonemia in the pediatric emergency care setting. Pediatr Emerg Care. 2010;26(12):888-891.

5. Whitelaw A, Bridges S, Leaf A, et al. Emergency treatment of neonatal hyperammonemic coma with mild systemic hypothermia. Lancet. 2001;358(9275):36-38.

6. Leonarda JV, Morris AA. Urea cycle disorders. Semin Neonatol. 2002;7(1):27-35.

7. Cagnon L, Braissant O. Hyperammonemia-induced toxicity for the developing central nervous system. Brain Res Rev. 2007;56(1):183-197.

8. Lichter-Konecki U, Nadkarni V, Moudgil A, et al. Feasibility of adjunct therapeutic hypothermia treatment for hyperammonemia and encephalopathy due to urea cycle disorders and organic acidemias. $\mathrm{Mol}$ Genet Metab. 2013;109(4):354-359.

9. Adevaa MM, Souto G, Blanco N, et al. Ammonium metabolism in humans. 2012;61:1495-1511.

10. McEwan P, Simpson D, Kirk JM, et al. Short report: Hyperammonaemia in critically ill septic infants. Arch Dis Child. 2001;84(6):512-513.

11. Martinez- Ortega RM, Tuya LC, PErez I, et al. El coeficiente de correlacion de los rangos de Spearman caracterización. Rev haban cienc méd La Habana. 2009;8(2).

12. Ozanne B, Nelson J, Cousineau J, et al. Thershold for toxicity from hyperammonemia in critically ill children. $J$ hepatol. 2012;56(1):123128. 